\title{
Notas sobre o método crítico de Gilda de Mello e Souza'
}

\author{
Otília Beatriz Fiori Arantes
}

Ao prefaciar, em 1987, O espírito das roupas ${ }^{2}$ - primeira edição em forma de livro de uma tese sobre $A$ Moda no século XIX, que sua autora praticamente relegara a um exílio de trinta e sete anos numa separata da Revista do Museu Paulista -, Alexandre Eulálio relembra o estado de verdadeiro "fervor intelectual" com que um ensaísta da envergadura de Augusto Meyer concluíra a leitura daquele texto, se perguntando quem poderia ser afinal a autora daquele trabalho inteiramente fora do esquadro acadêmico, tanto pela originalidade temática quanto pela excepcionalidade da prosa.

Está claro que Gilda de Mello e Souza sempre soube do caráter desviante daquele estudo em relação às normas universitárias predominantes na época, para não falar da impressão de futilidade que o assunto costumava produzir na austera e prolixa sociologia de seu tempo. Se hoje ficou muito mais fácil admirar sem condições esse milagre acadêmico de meio século atrás, o que no entanto já não está mais ao nosso alcance, não digo nem repetir, é a possibilidade mesma de emendar, ainda que remotamente, na fluência inventiva de sua prosa de ensaio, na qual, para além do talento de cada um, estava sedimentada a experiência social e intelectual de toda uma geração que aprendera a pensar imaginando as virtualidades de um país ainda em formação.

Sendo esta a matriz histórica do irrepetível, não penso desfigurar o espírito livre do ensaísmo da autora, se destacar, para efeito de análise e interpretação de sua originalidade, uma questão aparentemente preliminar que se poderia chamar de "método". Como se verá, igualmente idiossincrático.

* professora aposentada do Departamento de Filosofia da FFLCH-USP.

1 Redigidas a partir da Aula-Conferência "Um capítulo brasileiro da Estética e da História da Arte: Gilda de Mello e Souza", apresentada na abertura do II Congresso de Estética e História da Arte - Arte brasileira, no Programa de pós-graduação interunidades de Estética e História da Arte, no MAC USP, no dia 8 de novembro de 2005.

2 São Paulo, Cia. das Letras, 1987. 
Há exatamente 20 anos saía o livro do historiador italiano Carlo Ginzburg, Mitos, emblemas, sinais. Lembro de Gilda comentar o quanto se sentiu lisonjeada reencontrando num autor famoso uma explicação erudita de dois métodos de abordagem da obra de arte que lhe eram por assim dizer desde sempre como que congenitamente próprios e que, além do mais, não gozavam de muito prestígio entre os críticos locais, a saber: a arqueologia visual dos mestres da escola de Warburg e o método indiciário praticado pelos connaisseurs, notadamente pelo mais conhecido deles, o médico italiano do século XIX, Giovanni Morelli. Um pouco por temperamento, mas sobretudo por uma escolha muito meditada, Gilda sempre valorizara, na interpretação das obras, aquilo que aparentemente era desimportante e que não aparecia de imediato numa primeira leitura ou a olho nu, os pequenos indícios a serem perseguidos, como as pegadas, por um caçador, ou os "sinais" característicos que despertam a imaginação de um detetive, de modo a decifrar o enigma que nos é proposto pela obra, fosse ela quadro, filme, ou livro. Por outro lado - já então na linha de Aby Warburg, Panofsky, mas sobretudo Gombrich - acreditava que a interpretação de uma tela pelo crítico, tanto quanto da realidade pelo artista, eram sempre mediadas por um esquema dado, um modelo relacional, por isto mesmo variável, incerto, e que se pauta por algo que os psicólogos chamam de trial and error.

Porém, a questão que se colocava para a aficcionada brasileira daqueles métodos sem prestígio não era exatamente o da atribuição de autoria da obra, nem se tratava de peritagem no sentido estrito do termo, mas de algo como uma descoberta dos "códigos". Recordo-me da advertência recorrente que fazia em aula, sobre a necessidade de dominarmos os "códigos" - seja os adotados pelo artista em geral de forma espontânea, como no caso dos fragmentos menos trabalhados e por isso mesmo capazes de fornecer as pistas essenciais, como pretendia Morelli, seja nas repetições, nem sempre intencionais por parte do artista, das soluções adotadas através da história da pintura. Recorde-se que tanto Gombrich quanto Wöllflin (observadas as devidas distâncias) acreditavam que o que o artista realmente pinta, ele o deve mais aos outros pintores do que à observação direta.

Mas é preciso também não esquecer, ao falar dos "pequenos gestos inconscientes", como o faz por exemplo Edgar Wind, comentando Morelli, do que o próprio Freud - outra fonte inesgotável que Gilda sabia utilizar como ninguém com a devida parcimônia - escreveu, a propósito do perito italiano: "creio que o seu método está estreitamente aparentado à técnica da psicanálise médica. Esta também tem 
por hábito penetrar em coisas concretas através de elementos pouco notados ou desapercebidos, dos detritos, dos refugos". ${ }^{3}$

Um método ensaístico desses, que por assim dizer parecia não ir direto ao ponto, aparentemente incapaz de captar o essencial ou a estrutura geradora de uma obra, por isso mesmo desconcertava os seus pares, intrigados com tanta despretensão teórica. E no entanto o fascínio de suas aulas e escritos derivava em grande parte desse poder divinatório das "pistas" que ia levantando. Carlo Ginzburg usara a imagem de um tapete sendo tecido diante de nossos olhos.

Talvez, ou melhor, com certeza, se possa acentuar ainda mais a originalidade do método crítico de Gilda de Mello e Souza com a ajuda dos elementos que, não por acaso, ela soube tão bem reconhecer em funcionamento na imaginação sempre acesa de um Paulo Emílio para o detalhe revelador de toda uma cinematografia. ${ }^{4}$ Repassando os argumentos, mais do que apenas destaca, a rigor está se identificando com o relativo desinteresse do crítico pelos grandes temas e pelas teorias em voga (aliás, marca registrada de todo o grupo Clima), para voltar-se para o não consagrado, os mestres menores, no caso em exame o nosso cinema acanhado e rudimentar, em sua fase primitiva, buscando aí, no contato direto com a obra, decifrar o que ela, mesmo na sua expressão mais tosca e incipiente, ou por isso mesmo, e através de meios escassos, como em geral ocorria na filmografia brasileira nascente, tinha a dizer sobre o mundo, o nosso "mundo tímido e arcaico". A seu ver, mais do que a expressão de um temperamento pouco convencional, uma visão muito refletida e incrivelmente próxima do método indiciário, cuja aclimatação brasileira está nos interessando destacar. Centrado na observação do que parece não ter importância, justamente - relembra então explicitamente seu repertório pessoal - o modo de ver as obras que dera origem na crítica de arte do oitocentos à figura do "perito", no sentido de "conhecedor", como o definiu Lionello Venturi ${ }^{5}$ : aquele que "sabe confrontar e distinguir, de modo crítico, a escola, a personalidade, o estilo do artista”, que é capaz de "um exercício crítico minucioso, paciente, centrado na observação das características mais insignificantes".

3 Citado por Ginzburg em Mitos,emblemas, sinais, São Paulo, Cia. das Letras, 1989, p.147.

4 Refiro-me à sua argüição à tese sobre Humberto Mauro, retomada em "Paulo Emílio, a crítica como perícia", reproduzido em Exercícios de leitura (título da coletânea já nele mesmo bastante sugestivo em relação ao que estou tentando caracterizar),S.Paulo, Duas Cidades, 1980.

5 Num capítulo de sua História da Crítica de Arte, citado e comentado por ela. 
Numa palavra, como aliás se pode ler na orelha da edição francesa do livro de Paulo Emílio sobre Jean Vigo, cujo autor de resto se mostra instruído acerca das manias investigatórias do crítico brasileiro: para esclarecer os seus enigmas, foi necessário que Paulo Emilio se fizesse "paciente como um explorador, metódico como um egiptólogo, desconfiado como um detetive e sutil como só ele." Quando tempos depois o crítico passaria a desnudar a condição colonial sob cuja marca cruel se desenrolaria tudo o que se referia à produção cinematográfica brasileira, sua egiptologia exploratória seria bem diversa, sem falar na desconfiança detetivesca rearmada pela nova consciência do subdesenvolvimento.

Mas voltemos ao comentário luminoso de Gilda. Alguns "detalhes" sobre roupas e chapéus valem a citação, pois recortadas do contexto pelo olhar igualmente perito e não menos sutil de nossa autora: "é sobretudo através da vestimenta que o filme preestabelece e predetermina como será cada figurante. Em na Primavera da Vida é a roupa que nos informa desde o início que o Dr. Passos, mocinho que veio da cidade grande ... em oposição aos homens probos da cidade pequena, que usam colete e colarinho alto e engomado de pontas quebradas, dispensa o colete, usa paletó e gravata ... Além do mais o seu terno é de casimira e diverge neste detalhe dos costumes de linho branco..." $\mathrm{Ou}$ ainda: "0 chapéu do mocinho, sempre presente em suas mãos ou na cabeça, tem a fita larga e a aba curta descida sobre o rosto, enquanto o do vilão é uma 'suspeita palheta janota'; os delinqüentes locais trazem chapéus 'amarfanhados e até informes devido ao uso ostensivo' e, quanto ao coronel e seus amigos, surgem de cabeça nua, mas, como lembra com senso de humor Paulo Emílio, neles assentaria muito bem o chapéu coco. ${ }^{6}$ Creio que não se poderia visualizar melhor o encaixe quase sob medida entre o sexto sentido da perícia-crítica e o relevo ainda desconexo de uma cena periférica.

0 estudo de Carlo Ginzburg é um pouco posterior à redação da argüição de Paulo Emílio, mas se na época a referência principal da Profa. Gilda era Lionello Venturi, como víamos há pouco (e aqui mais uma reminiscência do tempo de aluna: o rito de iniciação para os alunos de graduação principiava pela leitura do "manual" de Venturi Para compreender a pintura, de Gioto a Chagall), circulava entre nós, já em meados da década de 60, traduzido pela Taurus, o livro de Edgar Wind Arte e anarquia, citado por mim no início, e não por acaso ligado à escola de Warburg, no qual 
dedica um capitulo especial à demolição dos preconceitos contra os connaisseurs. Aliás é graças a uma observação muito característica de Wind que Ginzburg encontra seu caminho para identificar isso que chama de novo "paradigma indiciário": "qualquer museu estudado por Morelli adquire imediatamente o aspecto de um museu criminal".

Sabemos aliás, segundo conta o mesmo Wind - reproduzindo um comentário do próprio Freud - que Morelli, então assinando com o pseudônimo de Ivan Lermolieff, um especialista russo traduzido para o alemão por Johanes Schwartze (respectivamente anagrama e tradução do seu verdadeiro nome, Giovanni Morelli) provocou uma imensa revolução nos museus ao questionar a autoria de várias obras (46 só no museu de Dresden).

Se é possível opor, como faz Gilda, a peritagem de Morelli às grandes teorias estéticas do início do século, em parte empenhadas em discutir o belo ideal - tanto faz se clássico ou medieval - não há como deixar de associar sua maestria técnica (ainda na esteira de Edgar Wind) à valorização da escrita aforismática e fragmentária dos primeiros românticos como Novalis e os irmãos Schlegel, sem falar na tradição do esboço, cultivado como um gênero autônomo, enfim, a tudo que está ligado na história da pintura à crise do academicismo e ao nascimento da pintura moderna: dos grandes românticos franceses, passando pela Escola de Barbizon, aos impressionistas. Sem contar que foram eles, como insistia nossa autora, que fizeram avançar a história da arte, que souberam tanto descobrir um Vermeer quanto corrigir uma série de atribuições falsas e reputações duvidosas.

Ainda segundo Ginzburg, se o método pericial não chega a ser científico e depende muito do "faro, do golpe de vista, da intuição" do crítico, algo tem a ver com a pesquisa científica e os dados documentais que vão reaparecer em outras áreas, das ciências humanas nascentes à literatura, especialmente no romance dito policial. Assim não é nada casual, continua, o parentesco entre Morelli, dissecando orelhas e mãos para identificar a autenticidade das telas, com um outro médico escritor, daquele mesmo século, Conan Doyle, cuja semelhança chegava por vezes à coincidência de recorrer justamente à observação minuciosa de tais órgãos como prova do crime. Em "A caixa de papelão", por exemplo, num certo momento Watson se surpreende com a atenção de Sherlock Holmes fixando o olhar nas orelhas de uma certa personagem, semelhante às que, decepadas, tinham sido enviadas numa caixa a uma pobre senhorita, levando-o a concluir que se tratava de uma parente da vítima...

Paralelo com o trabalho do detetive, que, diga-se de passagem, não tem em nada o intuito de rebaixar o mé- 
todo de Morelli, pelo contrário, pois, logo a seguir, Ginzburg enaltece Proust, sustentando que a Recherche também foi composta segundo um rigoroso método indiciário. E, seguindo esta linha de cruzamentos, não podemos deixar de lembrar que Aby Warburg sustentava que a marca identitária das figuras do Quattrocento florentino era mais do que tudo a representação do movimento do corpo, cabeleiras e vestes. Tais esquemas, segundo Gilda, funcionavam justamente como grandes filtros mediadores orientando o olhar que os artistas posteriores lançariam sobre a realidade. Mas aqui já ingressamos no capítulo Gombrich.

Pois é neste vai e vem entre a pintura, sua história e a realidade que se move a nossa autora - utilizando permanentemente e ao mesmo tempo relativizando as lições dos mestres da Escola de Warburg. Não eram poucas as referências em aula às dobras das roupas ou à postura dos serviçais nas pinturas dos holandeses, tanto quanto ao tratamento homogeneizador das figuras na tela e os objetos da vida doméstica daqueles interiores - veja-se A Leiteira, de Vermeer; ou à carnadura lisa, polida como os belos corpos das esculturas gregas ou mesmo como as estatuetas de biscuit, das figuras femininas de um Ingres, tão distantes da realidade e tão racionalmente construídas - exemplares justamente do contraste entre o linear e o pictórico na pintura, da diferença entre clássicos e românticos, Ingres e Delacroix ou Géricault.

Aliás, em se tratando de Ingres, um parêntesis: em sua tese sobre a moda no século XIX, embora se valendo, especialmente na última edição, de iconografia brasileira do período, numa certa altura toma como termo de comparação entre a vida doméstica naquele século e o extravasamento próprio à época renascentista, com o seu esplendor, justamente a postura feminina bem composta dos desenhos de Ingres, "o pintor mais característico da nova ordem" - diz ela -, ou na fotografia nascente, quando "o braço feminino não resvala mais, lânguido, sobre a roupa do homem; pousa recatado no braço do marido, respeitando uma ordem que não permite transbordamentos".

A esta altura não posso deixar de remeter o leitor a um registro histórico inestimável: a entrevista felizmente gravada em vídeo que Gilda concedeu a Carlos Augusto Calil em 1992, e que hoje acompanha a edição em DVD de Violência e Paixão de Luchino Visconti. Não me parece ocioso acrescentar que Gilda era uma apaixonada e exímia admiradora do grande cinema italiano da era dos realiza- 
dores-autores, como Visconti, Antonioni, Fellini, sobre os quais também escreveu ensaios exemplares. Acontece que no referido Violência e Paixão, na inepta tradução brasileira do original inglês Conversation Piece, podemos finalmente observar em cena, atuando inclusive como o real protagonista de um desencontro histórico - no huis clos sufocante de um ambiente familiar degradado na Itália convulsionada dos anos 70 - o conoscitore, além do mais colecionador, no caso, do gênero de pintura inglesa do século XVIII que dá título ao filme. Com direito inclusive a um lance inusitado de atribuição, pois o reconhecimento do automatismo autoral revelador se deve à compulsão das chamadas telefônicas do ex-agitador meia-oito encalacrado e cujas ambições estudiosas rifadas comovem o Professor, não por acaso inspirado na figura e ambiência do erudito Mario Praz. Mesmo renunciando a comentar a entrevista de Gilda, não resisto à simples menção de uma observação sobre o espírito indicial das roupas: o contraste entre a extrema vulgaridade dos modos, a elegância perfeita da vestimenta, sem falar na beleza fria da máscara facial da Condessa Brumonti (Silvana Mangano) compõem propriamente a figura de um monstro, mais ou menos à imagem e semelhança - subentendamos - dos sombrios personagens conspirando nos bastidores da cena política italiana da época. Isso dito, fujo igualmente da tentação de me aventurar no comentário de sua versão da filmografia de Antonioni - para que se tenha uma idéia do fio da meada a ser puxado, basta recordar a cena das ampliações fotográficas no Blow-up, e tudo o que daí se segue em matéria de meditação estética em chave "indiciária".

Ainda que de relance, não posso todavia deixar de mencionar um derradeiro desdobramento do Espírito das Roupas, as notas inéditas sobre Fred Astaire que fecham seu último livro publicado em vida, A idéia e o figurado - outro título sugestivo como ele só. Recordo que Gilda sempre pensou a moda como um fenômeno estético situado, em função dos enquadramentos sociais que a definem, no entrecruzamento das artes ditas maiores - como a pintura, a literatura, etc. - e das menores, entre elas a dança; conjugando gestos e atitudes pela mediação social das roupas, como arte rítmica incomparável. Aqui o lugar de sua admiração irrestrita e originalíssima por Fred Astaire, a seu ver o maior bailarino do século XX, o grande dançarino da vida moderna. Uma modernidade afirmativa e positiva, se é que se pode falar assim, e sonhar com suas promessas nos anos 30 . Uma aposta enfim do "homem ancorado no cotidiano, sem nostalgia nem ressentimento", a ponto de inverter o sinal opressivo do traje que o século XIX consagrara e "Baudelaire designava como uniforme de papa-defuntos: a casaca 
preta, a cartola que repetia a chaminé das fábricas, num despojamento que o instala no grau zero da vestimenta, reduzida ao preto, o branco, o gesto [...] puro arabesco sem cor". Mas vou parando por aqui para retornarmos às expressões locais.

Para tanto, ainda ficando nesta linha de decifração indiciária da realidade na obra - seja no espírito das roupas ou dos gestos - lembro o admirável ensaio sobre "Macedo, Alencar, Machado e as roupas", também incluído no último livro, onde as descrições de Macedo refletiriam, segundo a autora, a opinião conservadora dominante da burguesia média; as de Alencar, a visão bem mais complexa que deriva da urbanização e das novas formas de sedução; já as de Machado, ao contrário, representariam uma ruptura "bem mais sutil e elaborada", exprimindo desde o início uma clara consciência quanto à função diversa que a vestimenta desempenhava para o grupo masculino e o grupo feminino. "No primeiro caso ela cumpria sobretudo um papel civil, definidor do status e instaurador de uma identidade fictícia, mas pacificadora; no segundo, era o auxiliar eficiente do jogo erótico, num momento social instável, ambíguo, de conquistas recentes e aspirações sufocadas. Nos dois casos, a meditação sobre a vestimenta foi a máscara oportuna que utilizou para, bem protegido, lançar farpas contra a sociedade arrivista, puritana e insatisfeita."... "Mas a crítica daquele tempo, freqüentemente viciada pelas asperezas do Naturalismo, nem sempre entendeu o aspecto inovador da abordagem de Machado de Assis."

Aqui um dos nós teóricos a desatar nesta técnica ensaística "indiciária" verdadeiramente sem paralelo em nossa tradição: os enigmáticos momentos de ruptura, que conviria então grifar com a devida ênfase como neste caso de Machado de Assis, com a inércia subterrânea dos estilos, legitimados pela carga dos códigos perceptivos herdados. Sem falar no problema correlato da incerta adaptação dos referidos esquemas visuais aos supostos dados imediatos da observação. Códigos europeus, no caso, e realidade bruta nacional. Dilemas e ambigüidades, que são da nossa arte, e acredito reaparecem na crítica de Gilda, obrigando-a a ir além do que o esquema de Gombrich, sempre invocado, possibilita.

Em se tratando de pintura, um caso semelhante de mudança de código teria se dado, segundo a autora, com Almeida Júnior, como explica no catálogo de uma exposição

7 Souza, Gilda de Mello e, A idéia e o figurado, SP, Duas Cidades, Editora 34, 2005, pp. 88 e 89. 
no Museu Lasar Segall sobre os precursores imediatos dos Modernistas. ${ }^{8}$ Recuando ainda mais no tempo dos artistas ali representados, chama a atenção para o fato de que, com Almeida Júnior, ingressara pela primeira vez na nossa pintura o "homem brasileiro", mais exatamente, na pessoa do caipira paulista. ${ }^{9}$ Não um figurante a mais, como o índio dos cronistas, o negro dos viajantes estrangeiros, ou ainda a pequena legião retórica de iracemas e moemas de ateliê, imobilizadas na pose convencional da ninfa neoclássica ou romântica. Nem confinamento da sempre demandada singularidade nacional ao registro escrupuloso da aparência externa. É que a seu ver, o mérito incontestável de Almeida Júnior não deriva do simples fato de ter pintado o caipira com escrúpulos de etnólogo, porém reside nalgum modo inédito de notação visual que lhe permitiu surpreender a verdade profunda de um novo personagem.

Não se tratava assim de um mero assunto mas a rigor de uma estrutura, mais exatamente, uma "estrutura relacional", recorrendo ainda uma vez aos esquemas de Gombrich. Algo como a conversão da figura em forma, do caipira em caipirismo imanente. Mais exatamente: a verdade dos gestos da nossa gente. Foi isso que Gilda viu, e até onde podemos saber, ninguém mais antes dela. Sem exagero, acuidade de observação que ela compartilha com o artista.

0 caipira de Almeida Júnior não é portanto um figurante a mais, um tipo pitoresco entre tantos outros ditados pela força da percepção convencional, justamente porque nele se deixa ver pela primeira vez, para além da casca tradicional da aparência externa de repertório, a dinâmica dos gestos. E vice-versa: o regionalismo inédito de Almeida Júnior é a revelação de que a verdade profunda de um personagem a um tempo real e imaginado denominado "homem brasileiro" se expressa de preferência nas assim chamadas (no caso, pelos antropólogos, especialmente Mauss) técnicas do corpo.

Veja-se uma tela de mocidade como $O$ Derrubador, pintada em Paris em 1871. Nela, as técnicas de corpo do brasileiro (e nossa autora está convencida de que elas existem e podem ser identificadas) trariam também a marca do Realismo francês, muito presente na massa eloqüente do rochedo ou na veemência monumental, por exemplo dos pés

8 "Pintura brasileira contemporânea", em Souza, Exercícios de Leitura.

9 Retomo aqui parcialmente o estudo "Moda Caipira", redigido em coautoria com Paulo Eduardo Arantes, publicado num número da revista Discurso em homenagem à Profa. Gilda (n²6, 1996,pp. 33-68) e em Sentido da formação - três estudos sobre Antonio Candido, Gilda de Mello e Souza e Lúcio Costa, SP, Paz e Terra, 1997. 
do personagem; todavia não se poderia dizer que sejam verdadeiramente nossos, salvo para efeito pitoresco de reconhecimento do caráter local da cena, os demais elementos da composição, como os coqueiros, a atmosfera tropical do pequeno trecho de paisagem, ou até mesmo as feições mestiças da figura; nosso mesmo, de fato, é antes de tudo "o jeito do homem se apoiar no instrumento, sentar-se, segurar o cigarro entre os dedos, manifestar no corpo largado a impressão de força cansada".

Consideradas as coisas por este prisma, estamos diante de um efetivo marco zero, porém sob um duplo aspecto. A primeira dimensão já nos é familiar, a descoberta pictórica do "homem brasileiro", definido agora pela singularidade intransferivel de seu comportamento corporal; a segunda, tem a ver com as condições de tal revelação: "notação milagrosa do gesto”, concede Gilda (e aqui o problema também é teórico - apesar das reticências - e não é desprezível), pois Almeida Júnior empreendera sozinho e "sem precursores, lutando contra as reminiscências artísticas” (diz ela) que lhe impunham a cada momento outros modelos de pintura, mais nobilitadores sem dúvida, como exigia o estilo elevado que podia observar à sua volta.

Podemos nos perguntar: onde então a inocência do olhar pressuposta numa tal redescoberta do Brasil? Como este último se dá a conhecer numa dinâmica muito específica dos gestos, a fonte daquela necessária inocência perceptiva deve ser procurada em algo como a "memória do corpo", onde residem os nexos profundos que ataram a sensibilidade do artista à realidade nova do país. Memória social por certo. Mas e Gilda, como pôde ver tudo isso? Como já tive oportunidade de lembrar ${ }^{10}$, em primeiro lugar, por evidente empatia (embora em si mesma condição obviamente insuficiente), sendo ela mesma menina de fazenda do interior paulista. E, finalmente, por ter podido associar a esse dom perceptivo oriundo da "memória gravada no corpo" de que falávamos, o hábito da atenção para o detalhe revelador cultivado pela sua geração de críticos. Ou seja, conseguiu ver também porque viu com olhos de perito educado pelo longo tirocínio na observação direta da história da arte.

Cabe aqui, no entanto, um novo parêntesis (agora, metodológico): talvez valha a pena referir a ressalva de Ginzburg, ao concluir seu ensaio sobre Gombrich: "A história (as relações entre fenômenos artísticos e história política, religiosa, social, das mentalidades, etc.), expulsa silenciosamente pela porta, torna a entrar pela janela”. Evidentemente não teria cabimento naquele pequeno círculo de intelectuais

10 Refiro-me ao ensaio citado há pouco. 
formados no espírito dos modernistas, em especial Mário de Andrade, egressos da Faculdade de Filosofia, e preocupados em detectar os lineamentos da formação de uma arte brasileira, manter sem mais a orientação "imanentista" de um Gombrich, pelo contrário, não havia esquema da tradição européia que não fosse devidamente submetido a uma espécie de aclimatação crítica reveladora dos termos em confronto. Como se sabe, providência elementar que valia todo um programa.

Familiaridade quase biográfica com a cultura do caipira paulista ao mesmo tempo que com toda a grande tradição artística nacional e estrangeira; observação sistemática da coreografia teatral ${ }^{11}$; constatação de que a moda, dependendo do gesto, à medida que se recompõe a cada momento de seu jogo com o imprevisto, é a mais socializada das artes: esses os elementos que talvez tenham contribuído mais de perto para a cristalização da sensação plástica de que o essencial do "homem brasileiro" deveria ser procurado no seu movimento corporal.

É razoável supor, dada a importância do livro sobre a moda oitocentista na organização das idéias de Gilda acerca das relações entre arte e sociedade, que nesse caso particular tenha prevalecido o filtro da moda apreendida como uma arte rítmica. E a ser assim, porque não pensar em continuidade, imaginando as telas regionalistas de Almeida Júnior como o primeiro capítulo de um inventário sistemático de algo como uma ritmia dos gestos brasileiros? Esse um possível nexo a escandir a linha evolutiva da figuração plástica da experiência nacional. Vale para o caboclo amolando o machado, picando o fumo, empunhando a espingarda, ponteando a viola, negaceando a caça, o que vale para o elegante que demonstra a todos como está afeito aos usos da sociedade movimentando os complementos imprescindíveis do vestuário - luvas, chapéus, bengalas. E no entanto, é inegável, num e noutro encontramos a mesma ritmia de gestos altamente codificada, tanto no matuto que reproduz posturas ancestrais, quanto na desenvoltura do dandy por mimetismo social. ${ }^{12}$

Ou ainda, numa surpreendente combinação de ambas - uma vez extirpado miraculosamente o viés mimético de nossas elegâncias de empréstimo -, vislumbrada na aparição, na curva de um rio amazônico, da figura mítica do maleiteiro, no episódio famoso do Turista Aprendiz, no qual

11 Também tradutora e autora teatral bissexta - cf. Costa, Iná Camargo, “Ensaismo teatral no Brasil”, em Discurso, SP, n.26, 1996.

12 Mas tudo isto desenvolvi com mais detalhes, em co-autoria com Paulo Arantes no artigo citado. 
Mário de Andrade julga por um momento ter se deparado com a alternativa civilizatória brasileira ao mundo dominado pela disciplina burguesa do trabalho. Mais uma vez resisto à tentação de restituir na íntegra o comentário magistral de Gilda ${ }^{13}$, que emenda aliás com sua interpretação de vida inteira sobre o caráter errático de Macunaíma, deslocado agora pelo "limbo ou nirvana da calmaria serena" em que evolui a figura emblemática do moço comido pela maleita. Devo apenas destacar de novo o foco privilegiado de sua atenção, a notação daquela mesma ritmia de gestos, a partir da qual, então, sua própria imaginação literária alça vôo e reencontra a "constelação de sinais" [grifo nosso] ${ }^{14} \mathrm{em}$ que Mário projeta a sua identificação com o Brasil. Melhor citar por extenso:

"Eis que na curva do rio, saindo do silêncio e do mistério, surge da selva uma embarcação, avançando pesada na batida dos remos. É um casco com seis remeiros, que traz na proa o chefe da tripulação e, viajando em pé, no barco oscilante, demonstrando familiaridade com a água, um homem de seus trinta anos. A barba feita, o terno de linho branco muito limpo, a 'sensação firme de decoro' que transmite, o 'ar de soberbia', revelam que era dono ou filho de dono de seringal. A pele morena, muito pálida, traía a maleita.

O narrador descreve com respeito e admiração o comportamento do moço, que alheio à curiosidade que provoca, sobe a bordo para tratar dos recibos e faturas e, indiferente a tudo em redor, indiferente à beleza civilizada das passageiras, passa sem olhar para ninguém. Apenas, por delicadeza natural, ao se aproximar das senhoras tira o chapéu nativo de palha e vai-se como veio. Sem olhar." 15

Nesse verdadeiro dandy da mata virgem, enfim, quem sabe, a reconciliação utópica com o corpo largado de força cansada dos caboclos de Almeida Júnior, sem falar, é claro, no acreano sublimado da rua Lopes Chaves.

Só para fechar o argumento: não custa lembrar que este último ensaio é todo ele um contraponto entre Mário de Andrade e Gilberto Freyre, tendo como ponto de partida as respectivas análises da obra de Cícero Dias. Frequentemente

13 "0 mestre de Apicucos e o turista aprendiz", em A Idéia e o figurado, cit. pp.49-70. Na versão original, citada em "Moda Caipira": "Do Brasil telier ao Brasil de ar livre" (conferência proferida num colóquio em homenagem a Richard Morse, nos Estados Unidos, em 1993)

14 Ibidem, p. 67.

15 Ibidem, p. 65-66. 
apresentados como antagonistas, o que não deixa de ser verdade, Gilda no entanto preferiu destacar naquelas duas personalidades tão diversas a demonstração viva do poder da imaginação artística na interpretação do país: com efeito, a geração que entre 1935 e 1940 saía da universidade, num momento muito especial entre o legado das vanguardas e a chegada prestigiosa dos especialistas, aprendera a pensar o Brasil confiando precisamente naquele poder de revelação da experiência estética. Quanto ao caso particular do autor de Casa Grande e Senzala, Gilda recorda que também ele se impôs à sua geração "pela maneira inovadora de interpretar o país através dos pequenos indícios". ${ }^{16}$

Novembro-Dezembro de 2005

16 Ibidem, p. 55. 